\title{
O tempo entre "competências e habilidades": uma análise das questões de História do Brasil nas provas do Enem
}

\author{
The time between "skills and abilities": an analysis of Brazil's \\ History questions in Enem
}

Juliana Miranda da Silva ${ }^{1}$

\begin{abstract}
Resumo: A partir da análise de questões sobre História do Brasil presentes em diferentes edições do Exame Nacional do Ensino Médio (Enem), este trabalho objetiva discutir como foram abordadas as percepções temporais e a construção do tempo histórico nas referidas questões. Busca-se aferir acerca tanto da construção de sentidos do passado, atribuídos a determinados eventos históricos, como as relações possíveis com o presente, no qual age o sujeito histórico e cria-se um horizonte de expectativa futuro. Discute-se ainda, a construção das questões a partir das competências e habilidades norteadoras do exame e o caráter interdisciplinar da prova. As análises concentraram-se nas provas de "Ciências Humanas e suas Tecnologias", área do conhecimento que contempla a avaliação das competências e habilidades pertinentes aos conhecimentos históricos articulados a outras disciplinas, como Sociologia, Filosofia e Geografia.
\end{abstract}

Palavras-chave: Enem. Tempo histórico. Ensino Médio.

\begin{abstract}
Based on the analysis of questions about Brazil's History presented in different editions of the Brazilian High School National Exam (Enem), this paper aims to discuss how temporal perceptions and the construction of historical time in these questions were approached. It seeks to assess both the construction of past senses, attributed to certain historical events and the possible relations to the present, in which the historical subject acts and it is created a horizon of future expectation. It also discusses the construction of the questions based on the skills and abilities which guide the exam and the interdisciplinary nature of the test. The analyses focused on the tests of "Human Sciences and its Technologies," an area of knowledge that includes the evaluation of skills and abilities relevant to historical knowledge articulated to other disciplines, such as Sociology, Philosophy, and Geography.
\end{abstract}

Keywords: Enem. Historical time. High school.

\section{Introdução}

De tempos em tempos, temáticas relacionadas à educação transpõem a escola e a academia, lugares de discussão e análise tradicionais, e passam a receber maior atenção por parte das pessoas, a partir principalmente de temáticas veiculadas pelas mídias. Na atualidade, fruto de

1 Mestra e graduada em História, Especialista em Educação, e doutoranda em História no Programa de Pós-Graduação em História da Universidade do Estado de Santa Catarina (UDESC), Florianópolis, SC, Brasil. ORCID: http://orcid.org/0000-0001-9741-2041. E-mail: jumirandasilva@gmail.com 
uma reforma encampada por meio de medida provisória ${ }^{2}$, o Ensino Médio tornou-se assunto recorrente nos jornais, telejornais e nas redes sociais digitais, acumulando críticos e apoiadores à referida reforma. Evidentemente, essa etapa da educação básica aparece diversas vezes associada ao período que antecede os vestibulares e a entrada no Ensino Superior. Entretanto, mesmo que em grande parte do tempo, de maneira mais restrita, o Ensino Médio e seus equivalentes tenham instigado discussões acerca de seu formato e real finalidade, jamais se chegou a um consenso.

Os eixos de discussão se multiplicam para além dos modelos propedêutico e técnico, de formação geral ou profissional, entre a oferta pública e privada, quando nos permitimos incluir perspectivas de análise que contemplem, por exemplo, o próprio sujeito para o qual o Ensino Médio é destinado, as suas relações dentro e fora da escola e as suas demandas como jovem em formação em um cenário de rápidas transformações tecnológicas e nas relações de trabalho.

Com a universalização do Ensino Fundamental e o exponencial crescimento de matrículas no Ensino Médio, a chegada de camadas até então excluídas dessa etapa da educação escolar nas décadas finais do século XX, questões relacionadas à qualidade do ensino ofertado, também passaram a encabeçar intermináveis debates. Atreladas a isso, as reformas estruturadas e aprofundadas a partir da década de 1990, associam a necessidade de mensurar investimentos e seus resultados, trazendo para o campo educacional a terminologia e a metodologia de áreas, como as usadas na administração e na economia. O diretor se tornou gestor, a formação do professor passou a figurar como "treinamento", o "custo/benefício" em nome da "flexibilização" demandada pelos novos tempos deram vazão a uma série de propostas que se voltam à punição ou a recompensa pelos responsáveis ${ }^{3}$.

A redemocratização e a construção de um novo arcabouço legal também contribuíram para a consolidação no Brasil de ideias de maior participação política e transparência nos gastos públicos. Assim, o empenho pela inserção da gestão democrática nas escolas também suscitou anseios por parâmetros mais seguros, que embasassem políticas públicas voltadas à qualidade do ensino ofertado.

Nesse contexto, no âmbito municipal, estadual e federal vimos multiplicarem-se avaliações externas e indicadores educacionais. O Enem - Exame Nacional do Ensino Médio, foi implementado em 1998, por meio da Portaria $n^{0} 438$, de 28 de maio de 1998, objetivando fundamentalmente avaliar o desempenho dos concluintes e egressos deste nível de ensino (BRASIL, 1998). Com o passar dos anos, o número de participantes cresceu significativamente, fruto de diversas medidas que tornaram o exame mais atrativo aos estudantes de escolas públicas, como a isenção da taxa de inscrição, a partir de 2001 e a possibilidade de obtenção de bolsas em instituições de Ensino Superior particulares por meio do ProUni - Programa

\footnotetext{
2 Em 2016, o então Ministro da Educação Mendonça Filho apresentou a Medida Provisória n ${ }^{0}$ 746, de 22 de setembro de 2016, que previa a reforma do Ensino Médio sem qualquer debate com educadores, pesquisadores, estudantes ou pais. O ministro alegou a urgência da reforma tendo em vista a piora dos resultados relativos ao Ensino Médio no Ideb - Índice de Desenvolvimento da Educação Básica, publicados menos de duas semanas antes da apresentação da MP. No ano seguinte, em 16 de fevereiro de 2017, o então presidente Michel Temer sancionou a Lei $\mathrm{n}^{\mathrm{0}} \mathbf{1 3 . 4 1 5}$, transformando a Medida Provisória em norma jurídica.

3 Refiro-me aqui às políticas de acountability ou políticas de responsabilização, influenciadas por experiências principalmente estadunidenses e inglesas.
} 
Universidade para Todos, a partir de 2004 (BRASIL, 2004). Com a utilização parcial ou total dos resultados do Enem como forma de acesso a diversas universidades públicas desde as suas primeiras edições e, mais tarde, a programas como o Ciência Sem Fronteiras ${ }^{4}$, estudantes do ensino privado também contribuíram para a ampliação do número de inscritos e um mapeamento mais abrangente dos concluintes do Ensino Médio.

Estruturada em quatro áreas do conhecimento, a avaliação realizada no Enem tem caráter interdisciplinar e vincula-se, segundo seu documento básico (BRASIL, 2002) a um conceito mais abrangente e estrutural da inteligência humana, ao realizar a aferição das estruturas mentais para além da memória, por meio de situações-problema que se aproximem das condições reais de convívio social e de trabalho.

Tendo em vista o número crescente de participantes, sua vinculação com programas governamentais e a dimensão nacional da prova, somos levados a concluir que os assuntos abordados anualmente no exame e a forma como estes são colocados nas questões exercem influência no currículo do Ensino Médio e na maneira como os conteúdos são organizados e abordados por professores e professoras em sala de aula. No que se refere aos conteúdos de História, presentes na prova de Ciências Humanas e suas Tecnologias figuram temas tanto de História do Brasil como de História Geral, articulando-se ainda a outras disciplinas.

A partir da análise de questões que privilegiem aspectos da História do Brasil presentes em diferentes edições do exame, o presente estudo objetiva discutir como foram abordadas especificamente as percepções temporais nas referidas questões. Busca-se aferir acerca tanto da construção de sentidos do passado, atribuídos a determinados eventos históricos, como as relações possíveis com o presente, no qual age o sujeito histórico e cria-se um horizonte de expectativa futuro. Discute-se ainda, a construção das questões a partir das competências e habilidades norteadoras do exame e o caráter interdisciplinar da prova.

\section{A estrutura avaliativa do Enem}

Nas últimas décadas, o número de concluintes do Ensino Médio no Brasil cresceu significativamente, fruto de políticas de inserção e manutenção de alunos e alunas nas escolas públicas. No entanto, o quadro de vagas no Ensino Superior não acompanhou a crescente demanda, principalmente nas universidades públicas. Como consequência, o que se percebia até a primeira década do século XXI, é que diante da acirrada concorrência, os estudantes advindos da rede particular de ensino, na maioria dos casos, com acesso a uma formação direcionada à realização de exames de seleção, acabavam por preencher a maioria das vagas das universidades públicas. Com a expansão das faculdades particulares, principalmente a partir dos anos 1990 e a necessidade cada vez maior de formação superior, essas tendiam a captar os estudantes das redes públicas, que por razões diversas não conseguiram ingressar

4 Criado pelo Decreto ${ }^{\circ}$ 7.642, de 13 de dezembro de 2011 durante o governo da Presidenta Dilma Rousseff, o programa ofertou bolsas de estudo em instituições de ensino internacionais para estudantes de graduação até 2016. Em 2017, foi reformulado e sofreu significativo corte de verbas, deixando de atender estudantes de graduação, restringindo sua oferta de bolsas aos alunos de pós-graduação (BRASIL, 2017). 
em uma universidade gratuita, mas que dispunham de algum recurso, na maioria dos casos, fruto de seu próprio trabalho, para pagarem suas mensalidades.

É de conhecimento geral a série de dificuldades enfrentadas pela rede pública de educação no País, onde a falta de professores e a desvalorização profissional e salarial destes, bem como a má distribuição de recursos, sejam eles para a aquisição e a manutenção de equipamentos e mobiliário ou mesmo para a compra de merenda de qualidade, contribuem para que haja uma formação significativamente diferenciada entre as camadas sociais. Atrelado a esses problemas estruturais, muitos jovens ingressam precocemente no mercado de trabalho e não dispõem de tempo integral para a formação voltada ao preparo para as avaliações institucionais de caráter conteudista, que funcionavam como exclusiva porta de entrada para o Ensino Superior.

Nessa conjuntura, o Enem surge como instrumento de política de avaliação integrando o Índice de Desenvolvimento da Educação Básica (Ideb), mas passa, ao longo de suas edições, a ampliar o seu papel de exame avaliador, tornando-se uma ferramenta de acesso a diversos programas governamentais. Ao completar dez anos de sua existência, por meio da Portaria n. ${ }^{\circ}$ 109, de 27 de maio de 2009, foram regulamentadas uma série de alterações no exame. De acordo com tal documento, além de ser compreendido como instrumento de avaliação, o Enem objetivaria também "democratizar as oportunidades de acesso à Educação Superior" (BRASIL, 2009), Desde as suas primeiras edições os interesses governamentais em utilizar o exame como ferramenta de acesso já vinham materializando-se com a crescente adesão de Instituições de Ensino Superior no uso da nota do Enem.

Tanto o Enem como os outros exames externos criados durante o governo do presidente Fernando Henrique Cardoso tiveram continuidade no governo seguinte, do presidente Luiz Inácio Lula da Silva. Todavia, no caso do Enem, significativas alterações em nível tanto de estrutura e como de objetivos do exame demarcaram posturas distintas por parte dos dois presidentes. A criação do ProUni, (BRASIL, 2004), e do Reuni (BRASIL, 2007), são emblemáticas e servem como um exemplo pertinente. Enquanto o Programa Universidade para Todos (ProUni), possibilitou a ocupação de vagas ociosas em universidades privadas por jovens de baixa renda, a partir de uma política de isenção de impostos, o Programa de Apoio a Planos de Reestruturação e Expansão das Universidades Federais (Reuni), foi responsável pela ampliação da rede de universidades federais e institutos de ensino federais, ambos programas colaborando para a inserção de camadas, até então, excluídas de formação universitária. Pode-se considerar ainda, a Lei n. ${ }^{\circ}$ 12.711, de 29 de agosto de 2012, sancionada já no governo da Presidenta Dilma Rousseff, pela qual passou a ocorrer a reserva de vagas para estudantes provenientes de escola pública, com percentuais para autodeclarados negros, pardos, índios e com baixa renda familiar5.

Além de compor a avaliação de medição da qualidade do Ensino Médio e servir como modalidade alternativa ou complementar aos exames de acesso aos cursos profissionalizan-

A Lei n. ${ }^{\circ}$ 12.711, de 29 de agosto de 2012 , dispõe sobre reserva percentual para famílias com renda per capta inferior a um salário mínimo e meio (BRASIL, 2012). 
tes pós-médios e ao Ensino Superior, o Enem foi criado objetivando oferecer uma referência de autoavaliação ao cidadão "com vista às suas escolhas futuras" (BRASIL, 1998), tanto no que compete à continuidade dos estudos quanto em relação ao mercado de trabalho. Nesse sentido, observamos a consonância das premissas do exame com a Lei de Diretrizes e Bases da Educação (BRASIL, 1996), que propõe para o Ensino Médio a formação para o exercício da cidadania, progressão no trabalho e em estudos posteriores.

Conforme mencionado anteriormente, o Enem sofreu alterações ao longo de suas edições e passou em 2009 por uma grande reforma em sua proposta de avaliação, mantendo a referência principal na articulação entre o conceito de educação básica e cidadania. Estruturado em uma matriz que focaliza na integração entre as diversas áreas do conhecimento e em cinco eixos cognitivos - dominar linguagens (DL), compreender fenômenos (CF), enfrentar situações-problema (SP), construir argumentação (CA) e elaborar propostas (EP), o exame ampliou o número de questões e subdivisão de competências e habilidades por área de conhecimento. Foi adotada também a metodologia de avaliação baseada na Teoria da Resposta ao Item (TRI), agrega valores diferentes às questões, dado o seu grau de dificuldade.

De acordo com o documento básico do Enem, "competências" são as modalidades estruturais da inteligência, ou melhor, ações e operações que utilizamos para estabelecer relações com e entre objetos, situações, fenômenos e pessoas que desejamos conhecer. As "habilidades" decorrem das competências adquiridas e referem-se ao plano imediato do "saber fazer". Por meio das ações e operações, as habilidades aperfeiçoam-se e articulam-se, possibilitando nova reorganização das competências (BRASIL, 2002). Observa-se nas competências e habilidades referentes à prova de Ciências Humanas e suas tecnologias, parte do exame que contempla as questões de história, referência à compreensão de aspectos consoantes à construção de processos históricos e diferentes temporalidades. Assim, buscou-se nas edições do exame posteriores a sua reforma, verificar a presença de conceitos temporais pertinentes ao estudo e à compreensão da História como duração, devir, evento, processo, estrutura, ruptura, continuidade, permanência.

\section{Análise das questões}

Consoante aos estudos pertinentes à didática da história, a consciência histórica, entendida, grosso modo, como a significação no tempo (CERRI, 2001), infere-se que as questões com as quais milhões de jovens brasileiros têm contato durante a realização da prova, contribuem para estabelecer modos de organização temporal desses estudantes. Além daqueles e daquelas que prestaram voluntariamente o exame, outros incontáveis estudantes acabam por realizar a leitura das questões, por meio de exemplificações nos livros didáticos, que também passaram a inseri-las nas listas de atividades, destacando, em alguns casos, exemplos de interpretação para a correta resolução das situações-problema propostas.

Dessa forma, é inevitável pensar, no mínimo, sob dois aspectos de influência que surgem a partir do contato desses jovens com questões que circulam em âmbito nacional. Primeiramente, $o$ 
fato de que o crescimento do número de estudantes que prestam o exame anualmente influencia as aulas do Ensino Médio. Como professora desse segmento há mais de 10 anos, pude perceber que, tanto os materiais didáticos publicados, como o olhar dos professores para a integração de conhecimentos e para as situações-problema são consequências da repercussão do Enem e da importância que o exame vem ganhando como alternativa ao modelo dos vestibulares tradicionais.

Outro aspecto que merece ser lembrado remete a determinadas temáticas abordadas nas provas, que por tratarem de assuntos e situações polêmicas foram acusadas de inclinações políticas. Aqui a referência se faz para além das questões de História, compreendendo que a consciência histórica é construída a partir do contato com informações diversas, que nos norteiam rumo à orientação temporal, que, todavia, está em constante disputa por diferentes grupos. Assim, de acordo com Cerri (2010, p. 10) mesmo que o trabalho de contínua formação para uma identidade histórica se estabeleça em torno de generalizações sobre uma "consciência histórica dominante", há que se ter em mente que concepções diversas entram em choque, buscando sobreporem-se. As discussões acerca do estatuto da família e de uma suposta ideologia de gênero são apenas dois exemplos que nos levam a pensar acerca dos embates atuais, que ganham dimensões maiores quando mobilizados em avaliações externas.

Infere-se ainda, que as articulações e as conexões relativas ao tempo serão necessariamente distintas nas quatro provas do Exame. Isto é, a compreensão do tempo nas questões de Física ou Geografia, por exemplo, não serão as mesmas nas questões que se relacionam com o tempo histórico. Mesmo fazendo uso de datações que seguem calendários e relativas a passagem do tempo físico, o tempo histórico é necessariamente um tempo humano, que carrega suas especificidades. O tempo histórico é um tempo coletivo ou um tempo social, no qual os indivíduos estão inseridos em práticas que podem influenciá-los em sua concepção temporal. Assim, conforme Barros (2013, p. 22) "as datas são apenas um instrumento a mais para a elaboração do tempo histórico, e para, a partir deste tempo, pensar problemas específicos”.

Para realizar a análise proposta neste artigo, foram selecionadas questões referentes à História do Brasil presentes nas edições dos anos de 2010 a 2016, que apresentassem em seus enunciados relação com percepções de temporalidade (INEP, 2016). Conforme já mencionado, os conhecimentos são divididos no exame por áreas, tendo em vista o caráter interdisciplinar das provas (BRASIL, 2002). A prova de Ciências Humanas e suas tecnologias contempla as disciplinas de História, Geografia, Sociologia e Filosofia, não sendo especificadas no exame quais questões são de cada disciplina. Por isso, ao realizar a seleção das questões foram consideradas pertinentes aquelas que apresentavam conceitos relativos à temporalidade e que expressavam, alguma operacionalização do tempo, seja por meio de relações entre diferentes períodos ou arranjos temporais distintos do tempo físico ou geológico.

Considera-se ainda, que as questões analisadas foram retiradas de provas do Enem já em seu novo formato, ou como passou a ser chamado, o "Novo Enem". Até 2009, o Enem era composto por 63 questões sem divisão por área. Com a reforma, as quatro áreas do conhecimento passaram a ter provas especificas, cada uma delas com 45 questões, mais a prova de redação. Nesse novo formato, além dos eixos cognitivos comuns a todas as áreas do conhecimento foram 
delimitadas as matrizes de referência para cada uma das quatro áreas, com competências de áreas e habilidades específicas. No caso da Matriz de Referência de Ciências Humanas e suas Tecnologias, o documento aponta seis competências de área e 30 habilidades (BRASIL, 2009).

A partir da adequação dos parâmetros que delimitaram as análises para esse artigo, realizou-se a leitura das competências e habilidades relacionadas especificamente à passagem do tempo, transformações e permanências que poderiam ser cobradas no exame. Na competência de área 1, que é "Compreender os elementos culturais que constituem as identidades", figuram entre as habilidades pertinentes "analisar a produção da memória pelas sociedades humanas" e "associar as manifestações culturais do presente aos seus processos históricos" (BRASIL, 2009). Na competência de área 3, descrita como "compreender a produção e o papel histórico das instituições sociais, políticas e econômicas, associando-as aos diferentes grupos, conflitos e movimentos sociais", destaco as habilidades "identificar registros de práticas de grupos sociais no tempo e no espaço" (BRASIL, 2009). e "avaliar criticamente conflitos culturais, sociais, políticos, econômicos ou ambientais ao longo da história" (BRASIL, 2009). E finalmente, na competência de área 5 , que é "utilizar os conhecimentos históricos para compreender e valorizar os fundamentos da cidadania e da democracia, favorecendo uma atuação consciente do indivíduo na sociedade", relaciona-se a habilidade "analisar as lutas sociais e conquistas obtidas no que se refere às mudanças nas legislações ou nas políticas públicas” (BRASIL, 2009).

Dentro do quadro de questões analisadas entre 2010 e 2016, 28 questões adequavam-se aos parâmetros traçados para essa pesquisa. Um dos aspectos observados remete ao fato de que nelas aparecem intersecções com diferentes momentos históricos, exigindo tanto um conhecimento conjuntural como a capacidade de identificar o encadeamento de eventos. A utilização de recuos e avanços temporais fora diversas vezes mobilizada nas questões selecionadas, a partir de diferentes fragmentos textuais, que apresentam interpretações distintas sobre um determinado momento ou sobre figuras do passado. Permanências e rupturas que ocorreram como consequências da passagem do tempo e das ações humanas também foram encontras em questões com esse formato.

Também são utilizados recursos, como imagens e gráficos, para agenciar determinadas interpretações. Exemplo pertinente aparece em questão presente no exame de 2012, no qual por meio de um cartaz utilizado durante a Revolução Constitucionalista de 1932 é feita referência ao bandeirantismo, mobilizando assim, símbolos capazes de fomentar a união dos paulistas contra o Governo Federal, que remetem ao passado "heroico" daquele estado (INEP, 2012, p. 5). As referências articulam assim, um movimento característico do período colonial, o bandeirantismo, utilizado como propaganda política em outro contexto, durante o governo de Getúlio Vargas.

Naquele mesmo ano (INEP, 2012, p.14), outra questão chama atenção por mobilizar períodos distantes temporalmente, mas que convergiam para a abordagem de um tema específico. Utilizando-se de uma passagem do sermão do Padre Antônio Vieira sobre os suplícios de Cristo, a questão indaga sobre a relação feita pelo padre português aos sofrimentos dos escravos nos engenhos de cana de açúcar brasileiros: 
Em um engenho sois imitadores de Cristo crucificado porque padeceis em um modo muito semelhante o que o mesmo Senhor padeceu na sua cruz e em toda a sua paixão. A sua cruz foi composta de dois madeiros, e a vossa em um engenho é de três. Também ali não faltaram as canas, porque duas vezes entraram na Paixão: uma vez servindo para o cetro de escárnio, e outra vez para a esponja em que lhe deram o fel. A Paixão de Cristo parte foi de noite sem dormir, parte foi de dia sem descansar, e tais são as vossas noites e os vossos dias. Cristo despido, e vós despidos; Cristo sem comer, e vós famintos; Cristo em tudo maltratado, e vós maltratados em tudo. Os ferros, as prisões, os açoites, as chagas, os nomes afrontosos, de tudo isto se compõe a vossa imitação, que, se for acompanhada de paciência, também terá merecimento de martírio.

VIEIRA, A. Sermões. Tomo XI. Porto: Lello \& Irmão, 1951 (adaptado).

O trecho do sermão do Padre Antônio Vieira estabelece uma relação entre a Paixão de Cristo e
A) a atividade dos comerciantes de açúcar nos portos brasileiros.
B) a função dos mestres de açúcar durante a safra de cana.
C) o sofrimento dos jesuítas na conversão dos ameríndios.
D) o papel dos senhores na administração dos engenhos.
E) o trabalho dos escravos na produção de açúcar.

Temos assim, a relação entre a experiência do padre Antônio Vieira no Brasil, ao longo do século XVII, período de intensa exploração da mão de obra escrava na produção açucareira comparada aos suplícios de Jesus, símbolo maior da fé cristã. Atentemos ainda para o fato de o autor do registro ser um representante da estreita camada de letrados do país na época e o local de onde fala, como representante de uma das mais tradicionais instituições do Brasil, a Igreja Católica. Assim, o sofrimento dos escravos é comparado pelo padre ao sofrimento do próprio Cristo, 2000 anos antes.

Em prova do ano anterior (INEP, 2011, p. 11), por meio de uma tabela que demonstra o aumento proporcional do número de eleitores em relação à população geral, entre $1940 \mathrm{e}$ 2000, temos um exemplo de questão que mobiliza conhecimentos históricos e a capacidade de interpretação de eventos ligados à passagem do tempo. A questão abordou períodos no qual setores da sociedade ganharam direito ao voto, fruto de "lutas históricas", na qual os estudantes deveriam responder qual seria o acontecimento responsável pelo aumento do número de eleitores em um dado momento. Tanto nessa como em outras questões, foi observado que determinados contextos ou eventos são apresentados como "históricos", agregando-lhes assim caráter de relevância já no período em que ocorreram. Atenta-se ainda a apresentação de eventos-chave que criam temporalidades específicas, sobrepondo-se à divisão padrão da passagem dos anos, dotando de importância certos períodos, enquanto outros são relegados a segundo plano. No caso dessa questão especificamente, se criou um encadeamento específico de acontecimentos ligados ao aumento de número de eleitores, que transpôs a mera datação ano após ano, pois priorizou os acontecimentos mais significativos para que tal fato fosse possível. 
Também no ano de 2011, as disputas pelo significado de determinados conceitos e suas transformações ao longo da história, propõem uma interpretação imbricada em diferentes temporalidades. Em questão que diz respeito às disputas que ocorrem no debate político pela apropriação de conceitos como "democracia" e "reforma" na conjuntura das décadas de 1950 e 1960, observamos em seu enunciado excertos de dois textos que constroem usos distintos para os termos:

TEXTO I

A ação democrática consiste em todos tomarem parte do processo decisório sobre aquilo que terá consequência na vida de toda coletividade.

GALLO, S. et al. Ética e Cidadania. Caminhos da Filosofia. Campinas: Papirus, 1997 (adaptado).

\section{TEXTO II}

É necessário que haja liberdade de expressão, fiscalização sobre órgãos governamentais e acesso por parte da população às informações trazidas a público pela imprensa.

Disponível em: http://www.observatoriodaimprensa.com.br. Acesso em: 24 abr. 2010.

Partindo da perspectiva de democracia apresentada no Texto I, os meios de comunicação, de acordo com o Texto II, assumem um papel relevante na sociedade por

A) orientarem os cidadãos na compra dos bens necessários à sua sobrevivência e bem-estar.

B) fornecerem informações que fomentam o debate político na esfera pública.

C) apresentarem aos cidadãos a versão oficial dos fatos.

D) propiciarem o entretenimento, aspecto relevante para conscientização política.

E) promoverem a unidade cultural, por meio das transmissões esportivas.

Um dos excertos foi retirado do programa da União Democrática Nacional (UDN), de 1957 e nele a "construção do regime democrático" parece associada a uma ideia contrária a atos radicais ou extremistas tanto de direita como de esquerda. O excerto seguinte foi retirado do Manifesto do Comando Geral dos Trabalhadores (CGT) e data de 1962, defendendo a ação da classe trabalhadora, em prol da "constituição de um governo nacionalista e democrático" por meio da realização de reformas entre as quais estão a reforma agrária com extinção do latifúndio, a reforma bancária e a regulamentação da Lei de Remessa de Lucros. Observamos assim, conforme Koselleck (1992) que a inteligibilidade de um conceito está imbricada em uma série de contextos, sobre o qual ele próprio atua na compreensão e na dotação de sentidos. Assim, o referencial histórico que o permeia é crucial para a sua compreensão e pode variar não apenas conforme o tempo, mas a partir de apropriações de diferentes grupos.

Outro exemplo de questão que problematiza a construção de conceitos aparece na prova de 2016 (INEP, 2016, p. 3), quando dois textos referentes às formas pejorativas pela qual os 
grupos nativos da América foram referenciados pelos europeus. A questão propõe que os estudantes identifiquem, a partir dos dois textos apresentados, a construção etnocêntrica de conceitos que generalizam uma imensa variedade de povos, tendo em vista a falta de interesse dos colonizadores com a diversidade cultural encontrada.

\section{TEXTO I}

Documentos do século XVI algumas vezes se referem aos habitantes indígenas como "os brasis", ou "gente brasília" e, ocasionalmente no século XVII, o termo "brasileiro" era a eles aplicado, mas as referências ao status econômico e jurídico desses eram muito mais populares. Assim, os termos "negro da terra" e "índios" eram utilizados com mais frequência do que qualquer outro. SCHWARTZ, S. B. Gente da terra braziliense da nação. Pensando o Brasil: a construção de um povo. In: MOTA, C. G. (Org.). Viagem incompleta: a experiência brasileira (1500-2000). São Paulo: Senac, 2000 (adaptado).

\section{TEXTO II}

Índio é um conceito construído no processo de conquista da América pelos europeus. Desinteressados pela diversidade cultural, imbuídos de forte preconceito para com o outro, o indivíduo de outras culturas, espanhóis, portugueses, franceses e anglo-saxões terminaram por denominar da mesma forma povos tão díspares quanto os tupinambás e os astecas.

SILVA, K. V.; SILVA, M. H. Dicionário de conceitos históricos. São Paulo: Contexto, 2005.

Ao comparar os textos, as formas de designação dos grupos nativos pelos europeus, durante o período analisado, são reveladoras da:
A) concepção idealizada do território, entendido como geograficamente in- diferenciado.
B) percepção corrente de uma ancestralidade comum às populações ameríndias.
C) compreensão etnocêntrica acerca das populações dos territórios conquistados.
D) transposição direta das categorias originadas no imaginário medieval.
E) visão utópica configurada a partir de fantasias de riqueza.

Observamos assim, que o cerne da questão consiste em perceber como, com o passar do tempo, o colonizador fez uso de termos que adquiriram outros sentidos, como exemplo a referência ao "brasileiro" ou "brasis" para designar os nativos de pele avermelhada que viviam no território brasileiro ou o "índio" para denominar povos tão distintos como os tupinambás e os astecas. Não há, portanto um questionamento direto sobre um evento estático, do qual o estudante deveria evidenciar informações memorizadas, mas justamente a problematização da passagem do tempo e seus efeitos sobre o uso de determinados conceitos.

A leitura de imagens, como a de fotografias também apareceu nas questões pesquisadas. Um retrato do século XIX foi utilizado em uma das questões da prova de 2011 (INEP, $2011 \mathrm{p}$. 9), na qual se problematizam os conhecimentos dos estudantes acerca de aspectos históricos 
da escravidão com a observação do vestuário da época. Temos nesse exemplo, o período histórico identificado no enunciado da questão e na legenda da imagem (século XIX). Mas o exercício de interpretação da imagem de época se faz necessário para identificar que a utilização de sapatos demarcava naquele período a distinção social entre escravos e não escravos.

A interpretação no presente de um passado em revisão também figurou entre as questões analisadas. Na prova de 2014, a temática em torno do funcionamento da Comissão Nacional da Verdade evocou a possibilidade de, por meio da análise de documentos e entrevista com envolvidos realizar esclarecimentos acerca de um período do passado recente, entre 1964 e 1988 (INEP, 2014, p. 10). Notamos assim, que a questão fez uso de diferentes fontes criadas ao longo de pouco mais de duas décadas para abordar possibilidades de análises, que evidenciam que as interpretações sobre o passado podem sofrer alterações e a memória de determinados períodos está em disputa.

Em 2015, a partir de uma charge de Ziraldo, outra questão abordou a entrada de capital no Brasil por meio de empréstimos, que começariam a ser pagos "daqui a dez anos" (INEP, 2015, p. 7). A charge apresenta o pai acariciando a cabeça do filho e exclamando "Tadinho", dando a entender que as futuras gerações, ali representadas pela criança, herdariam as dívidas contraídas até então. No enunciado podemos perceber que a charge data de 1977, período no qual ainda vigorava a ditadura militar e indaga acerca da captação de recursos estrangeiros no período. Temos assim, mais um exemplo de interpretação que exige a análise de imagens, nesse caso uma charge, associada a explicação fornecida pelo enunciado e que propõem analisar as consequências de ações presentes para as gerações futuras.

A prova de Ciências Humanas e suas Tecnologias aplicada em 2015 foi particularmente polêmica devido a questão que, a partir de um fragmento do livro O Segundo Sexo, escrito pela filósofa francesa Simone de Beauvoir abordou a luta pela igualdade de gênero nos anos 1960 (INEP, 2015, p. 15). Publicado originalmente em 1949, a utilização do excerto retirado do livro onde aparece a emblemática afirmação de Beauvoir de que "ninguém nasce mulher: torna-se mulher" trouxe à tona discussões que se estenderam para além do dia da prova. Nessa mesma edição, o tema da redação foi a persistência da violência contra a mulher, outra temática que gerou debates ao expor este flagelo da sociedade brasileira (INEP, 2015, p. 2). $\mathrm{Na}$ época, o governo ${ }^{6}$ foi acusado de usar o Enem como propaganda política da esquerda, por utilizar textos de escritores, que segundo os críticos teriam transformado o exame em palco para ideias “esquerdistas”. Em artigo publicado por Hélio Schwartsman na Folha de S. Paulo, o filósofo e jornalista acusou a prova de Ciências Humanas e suas Tecnologias de dar "generoso espaço a tópicos e autores caros à esquerda" e "disparar, ainda que levemente, conexões neuronais esquerdistas nos candidatos" (SCHWARTSMAN, 2015, p. 2).

As críticas e preocupações de setores mais conservadores às análises e objetos de estudo consoantes às Ciências Humanas, entretanto, não são novidade na história recente do Brasil. Duramente atacadas durante a ditadura militar (1964-1985), as "Humanas" foram cerceadas por vieses moralistas para darem lugar às disciplinas menos perigosas. História e Geografia foram

6 Em 2015, Dilma Rousseff, eleita pelo Partido dos Trabalhadores (PT) iniciou seu segundo mandato. 
substituídas do currículo do primeiro grau pela Educação Moral e Cívica, enquanto Filosofia e Sociologia, disciplinas que alicerçam a compreensão e a reflexão do ser humano como ser social e racional, deram lugar à Organização Social e Política do Brasil, no currículo do então segundo grau.

Embora com diferentes atribuições designadas às Ciências Humanas ao longo do tempo, estas, na busca de formar e compreender o ser humano, sujeito histórico, ser social e cultural, jamais abandonaram a interdisciplinaridade. E nos parece pertinente perceber que a construção das provas de área do Enem considere na composição das questões, ampla intersecção entre os conhecimentos, diferentemente dos tradicionais vestibulares, rigorosamente divididos por disciplinas. Assim, as diferentes interações entre contextos históricos e geográficos, entre dinâmicas compartilhadas por grupos, as gêneses e as transformações das sociedades são exemplos de interações entre conhecimentos que evidenciam a relevância da abordagem interdisciplinar objetivada pelo exame.

Da mesma forma, a adoção da análise da avaliação de competências e habilidades em oposição à tradicional avaliação de conteúdos adquiridos também pode ser entendida como uma opção de abordagem, que privilegia não só a compreensão das ações humanas, como coloca o estudante como agente nesse processo. Ao mesmo tempo, não exclui suas condições subjetivas, com seus anseios e questionamentos, reconhecendo que ao seu redor outros estão em igual condição.

A compreensão de processos que levam à alienação de direitos e que dizem respeito às dimensões materiais da existência humana convergem, inexoravelmente, a problematizações ligadas à cidadania e ao papel das instituições políticas, sociais e econômicas, à aplicabilidade e ao acesso à justiça e as diferenças entre direitos e privilégios. Nesse sentido, nos parece compreensível que, ao longo do tempo, as Ciências Humanas possam ter despertado certa preocupação daqueles que não veem com bons olhos oportunizar momentos de compreensão dos contextos sociais e históricos, capazes de suscitar questionamentos sobre o status quo. Todavia, a restrição de abordagens problematizadoras da realidade apenas aos exames de avaliação é de pouca valia se não ocorrerem também dia após dia, no chão da sala de aula.

\section{Considerações finais}

Embora as análises realizadas para a elaboração deste trabalho tenham restringindo-se às questões referentes à História do Brasil, a pertinência da temática suscita investigações futuras, considerando também as questões que abordam temáticas relacionadas à chamada História Geral. Nesse sentido, ampliar o olhar possibilitará explorar com maior fôlego a maneira como as habilidades pertinentes as relações entre temporalidades são mobilizadas no exame de maior dimensão do país.

Ao colocar-se, conforme seu material de divulgação, como um ensaio para a vida (BRASIL, 2012), esperava-se das questões do Enem maior relação com o presente. Tais relações ocorrem, embora de maneira tímida, associando aspectos atuais da sociedade com processos históricos, fruto de lutas sociais, embates políticos, disputa e ampliação por direitos e apropriações de conceitos. A inevitável leitura integral das provas para a seleção das questões permitiu perceber que o tempo presente foi usado como referencial em questões que contemplam as 
competências e habilidades de área da Geografia, e ainda, em menor escala, nas questões de Sociologia e Filosofia. Todavia, considerando o caráter interdisciplinar do exame, é compreensível que temáticas ligadas ao tempo presente suscitem questões que recorram a outras disciplinas e dialoguem com campos do saber diversos.

Diferentemente de outros exames avaliativos, que focam em conhecimento meramente acumulado, decorado, as questões analisadas evidenciaram a necessidade de compreensão do encadeamento de acontecimentos, deixando de focar em datações específicas, usando-as como instrumento conjuntural. Percebe-se assim, a presença de tempos distintos que se intercalam de diferentes maneiras nas questões, a partir da leitura de diferentes tipos de documentos históricos. A presença de larga variedade de documentos usados na elaboração e enunciado das questões proporciona aos estudantes a compreensão de que as experiências humanas podem ser registradas de diferentes maneiras e sob diferentes pontos de vista.

Um dos elementos mais característicos das questões, que abordaram elementos relativos ao tempo histórico, foi a construção dos enunciados, a partir de dois ou mais referenciais. Dois fragmentos de textos ou uma imagem e um texto eram usados para referenciar o assunto abordado, apresentando diferentes perspectivas, que em alguns casos, foram elaborados em momentos diferentes. A volatilidade dos usos do passado, a ressignificação de símbolos e figuras históricas através do tempo, o reconhecimento de patrimônios culturais, que outrora foram desconsiderados e as permanências arraigadas em nossa sociedade são exemplos de abordagens temporais nas questões analisadas. Nesse sentido, podemos inferir que a estrutura das questões privilegia distintas narrativas do passado ao evocar registros escritos ou visuais que se tornam fontes históricas quando mobilizados e nos ajudam a compor o tempo histórico, que é concomitantemente o tempo da narrativa da espécie humana e o tempo das experiências individuais (BARROS, 2013, p. 180). Evidencia-se assim, o distanciamento das questões aplicadas no Enem se comparadas a vestibulares tradicionais, que exigem a memorização de fatos isolados.

Reconhecem-se os avanços na proposta de avaliar por meio de competências e habilidades, mas é fundamental não restringir a avaliação do Ensino Médio à avaliação dos estudantes por meio da aplicação de exames. Da mesma forma, reconhecer o ato de avaliar como um direito, através do qual os envolvidos no processo educacional obtenham subsídios necessários ao desenvolvimento de estratégias para a melhoria da qualidade da aprendizagem é enxergar a educação sob uma perspectiva distante da tão arraigada cultura da performatividade. Cabe lembrar ainda, dos preceitos assegurados pela LDB, que versam sobre a educação não apenas para o mundo do trabalho, mas para o pleno desenvolvimento do educando.

\section{Referências}

BANCO MUNDIAL. Prioridades y estrategias para la educación. Washington, DC: Banco Mundial, 1996.

BARROS, José D’Assunção. O tempo dos historiadores. Petrópolis, RJ: Editora Vozes, 2013. 
BRASIL. Decreto 6.096, de 24 de abril de 2007. Institui o Programa de Apoio a Planos de Reestruturação e Expansão das Universidades Federais - REUNI. Diário Oficial da União Seção 1, Brasília, DF, p. 7, 25 abr. 2007.

BRASIL. Lei $n^{\circ}$ 12.711, de 29 de agosto de 2012. Dispõe sobre o ingresso nas universidades federais e nas instituições federais de ensino técnico de nível médio e dá outras providências. Diário Oficial da União - Seção 1, Brasília, DF, p. 1, 30 ago. 2012.

BRASIL. Lei $n^{\circ}$ 9.394, de 20 de dezembro de 1996. Brasília, DF, 1996.

BRASIL. Lei $n^{o}$ 13.415, de 16 de fevereiro de 2017. Diário Oficial da União - Seção 1, Brasília, DF, p. 1, 17 fev. 2017. https://doi.org/10.22420/rde.v11i20.773

BRASIL. Medida Provisória $n^{\circ}$ 746, de 22 de setembro de 2016. Diário Oficial da União - Seção 1, Brasília, DF, n. 184-A, p. 1, 23 fev. 2016.

BRASIL, Ministério da Educação, Instituto Nacional de Estudos e Pesquisas Educacionais. INEP. Documento Básico ENEM. Brasília, DF: INEP, 2002.

BRASIL. Plano Decenal de Educação Para Todos. Brasília, DF: MEC, 1993. Versão atualizada, 12op.

BRASIL. Portaria $n^{0}$ 109, de 27 de maio de 2009. Estabelece a sistemática para a realização do Exame Nacional do Ensino Médio no exercício de 2009. Diário Oficial da União: Seção 1, Brasília, DF, n. 100, p. 56, 28 maio 2009.

BRASIL. Portaria $n^{\circ} 438$, de 28 de maio de 1998. Institui o Exame Nacional do Ensino Médio. Diário Oficial da União - Seção 1, Brasília, DF, n. 102-E, Seção 1, p. 5, 1 maio 1988.

CERRI, Luis Fernando. Os conceitos de consciência histórica e os desafios da didática da história. Revista de História Regional, Ponta Grossa, v. 6, n. 2, p. 93-112, 2001.

CONFERÊNCIA Mundial de Educação para Todos. Declaração Mundial de Educação para Todos. Plano de Ação para Satisfazer as Necessidades Básicas de Aprendizagem. Brasília, DF: UNIFEC, 1990.

INEP, Instituto Nacional de Estudos e Pesquisas Educacionais Anísio Teixeira. ENEM 2010 Exame Nacional do Ensino Médio. Ministério da Educação. Disponível em: http://portal.inep. gov.br/provas-e-gabaritos. Acesso em: 3 jun. 2019.

INEP, Instituto Nacional de Estudos e Pesquisas Educacionais Anísio Teixeira. ENEM 2011 Exame Nacional do Ensino Médio. Ministério da Educação. Disponível em: http://portal.inep. gov.br/provas-e-gabaritos. Acesso em: 3 jun. 2019.

INEP, Instituto Nacional de Estudos e Pesquisas Educacionais Anísio Teixeira. ENEM 2012 Exame Nacional do Ensino Médio. Ministério da Educação. Disponível em: http://portal.inep. gov.br/provas-e-gabaritos. Acesso em: 3 jun. 2019.

INEP, Instituto Nacional de Estudos e Pesquisas Educacionais Anísio Teixeira. ENEM 2013 Exame Nacional do Ensino Médio. Ministério da Educação. Disponível em: http://portal.inep. gov.br/provas-e-gabaritos. Acesso em: 3 jun. 2019.

INEP, Instituto Nacional de Estudos e Pesquisas Educacionais Anísio Teixeira. ENEM 2014 Exame Nacional do Ensino Médio. Ministério da Educação. Disponível em: http://portal.inep. gov.br/provas-e-gabaritos. Acesso em: 3 jun. 2019. 
INEP, Instituto Nacional de Estudos e Pesquisas Educacionais Anísio Teixeira. ENEM 2015 Exame Nacional do Ensino Médio. Ministério da Educação. Disponível em: http://portal.inep. gov.br/provas-e-gabaritos. Acesso em: 3 jun. 2019.

INEP, Instituto Nacional de Estudos e Pesquisas Educacionais Anísio Teixeira. ENEM 2009 Exame Nacional do Ensino Médio. Ministério da Educação. Disponível em: http://portal.inep. gov.br/provas-e-gabaritos. Acesso em: 3 jun. 2019.

INEP, Instituto Nacional de Estudos e Pesquisas Educacionais Anísio Teixeira. ENEM 2009 Exame Nacional do Ensino Médio. Ministério da Educação. Disponível em: http://portal.inep. gov.br/provas-e-gabaritos. Acesso em: 3 jun. 2019.

LOPES, Alice Casimiro; LÓPES, Silvia Braña. A performatividade nas políticas de currículo: o caso do Enem. Educação em Revista. Belo Horizonte, v. 26, n. 1 p. 89-110, abril, 2010. https:// doi.org/10.1590/S0102-46982010000100005

KOSELLECK, Reinhart. Uma História dos conceitos. Estudos Históricos, Rio de Janeiro, v. 5, n. 10, p. 134-146, 1992.

SCHWARTSMAN, Hélio. A ideologia do Enem. Folha de S. Paulo, São Paulo, ano 95, n. 31.618, 27 out. 2015. Primeiro Caderno, p. 2.

Recebido em: 18/10/2018.

Aprovado em: 9/5/2019.

Juliana Miranda da Silva

Doutoranda em História - UDESC

EMAIL: jumirandasilva@gmail.com

ORCID: http://orcid.org/0000-0001-9741-2041

Instituição: Universidade do Estado de Santa Catarina - UDESC. Endereço Postal: Av. Me. Benvenuta, 2007 - Itacorubi, Florianópolis - SC. CEP: 88035-901 